\title{
OBRA DE ARTE COMO TERRITÓRIO DE EXISTÊNCIA
}

\author{
Andresa Ribeiro Thomazoni $\star$ \\ Tania Mara Galli Fonseca $\star \star$
}

\section{Resumo}

A Oficina de Criatividade, criada em 1990 no Hospital Psiquiátrico São Pedro (RS), constitui-se como espaço que possibilita a criação artística a usuários portadores de sofrimento mental. A partir do Acervo da Oficina de Criatividade, iniciamos uma pesquisa cartográfica da Coleção Luiz Guides, um dos frequentadores. Interessa-nos explorar os limites sensiveis entre vida e obra de um sujeito enclausurado há 60 anos no regime manicomial. Buscamos, então, uma exploração sobre as forças que atravessam esse corpo e cujas marcas de tinta nos apontam não somente aos gestos, mas também à criação de territórios existenciais.

Palavras-chave: arte; loucura; território de existência; cartografia.

\section{THE WORK OF ART AS A TERRITORY OF EXISTENCE}

\begin{abstract}
"Oficina de Criatividade" was established in 1990 in "Hospital Psiquiátrico São Pedro" (RS), it constitutes a space that allows users to create artistic mental patients. From the "Acervo da Oficina de Criatividade", began a cartographic survey of the Collection Luiz Guides, one of the attendees. We are interested in exploring the boundaries between life and sensitive work of a guy locked up for 60 years in the asylum system. We seek, therefore, an exploration of the forces that cross the body and whose ink marks, point us to not only gestures but also the creation of existential territories.
\end{abstract}

Keywords: art; madness; territory of existence; cartography.

^Psicóloga, Mestre em Psicologia Social e Institucional UFRGS, Doutoranda em Informática na Educação pela Universidade Federal do Rio Grande do Sul, integrante do grupo de pesquisa Corpo, Arte e Clínica nos Modos de Trabalhar e Subjetivar, membro da equipe do Acervo da Oficina de Criatividade do HPSP.

E-mail: andresa.thomazoni@gmail.com

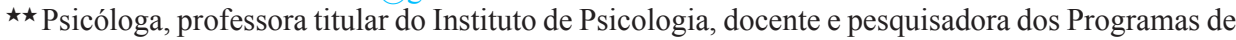
Pós-Graduação em Psicologia Social e Institucional e de Informática na Educação/ Universidade Federal do Rio Grande do Sul

E-mail: tfonseca@via-rs.net 


\section{"TORNA-TE O HOMEM DE TUAS INFELICIDADES, APRENDE A ENCARNAR TUA PERFEIÇÃO E TEU BRILHO"}

No contexto do Hospital Psiquiátrico São Pedro, o hospício mais antigo do RGS, fundado em 29 de junho de 1884, situa-se a Oficina de Criatividade. Tratase de um espaço criado em 1990, onde usuários-moradores desenvolvem, de forma livre, atividades de pintura, escrita, bordado e modelagem. Em conseqüência de seus 20 anos de existência, a referida Oficina acumulou as obras feitas pelos usuários, cabendo, então, ao seu Acervo armazenar essa volumosa produção plástica, que se estima ser em torno de cem mil obras. Deste arquivo, iniciou-se, em 2007, um projeto de extensão e pesquisas que articulam tanto Universidade como Hospital, somando esforços para a organização, catalogação e disponibilização desse valioso material artístico-cultural. Assim, busca-se visibilizar e problematizar as potências de criação que habitam sujeitos que foram, por sua loucura, enclausurados por longos anos. Nesse sentido, iniciou-se a catalogação de Quatro Coleções de artistas-loucos, sendo que nos ocupamos precisamente da Coleção Luiz Guides, ${ }^{2}$ pela qual demos início à nossa pesquisa cartográfica. ${ }^{3}$

Luiz Guides, paciente-artista da Oficina de Criatividade, nascido em 1922 e natural de Rio Grande, foi internado em 1950 no Hospital Psiquiátrico São Pedro, vindo a falecer em 2010. Os escassos dados dos prontuários médicos apontam para um silenciamento do tempo em que habitou a clausura. Foi no seu movimento de frequentar regularmente a Oficina de Criatividade que se deu um encontro de saúde, entre ele e as tintas. De uma rica expressão plástica, tal qual um arquiteto das cores, seus traços ganharam ritmo e plasticidade ao longo do tempo. Uma espécie de agenciamento entre "vida e obra" começou a ganhar contornos. Nasceu assim, a "Coleção Luiz Guides", composta de guache sobre papel e estimada em torno de 4.500 obras.

Nossa pesquisa, buscou instaurar uma geografia de afetos, orientada pelo princípio cartográfico, constituindo assim um tipo de sensibilidade na exploração da "vida e obra". Não buscamos falar de um sujeito, enquanto ego ou identidade, mas dos rumores expressivos que são capazes de atravessar um corpo. Nosso olhar é de exploração das forças que o atravessam e que se dobram ${ }^{4} \mathrm{em}$ imagens, cuja paisagem abriga forças ${ }^{5}$ e intensidades.

Assim, entendemos a obra como expresso de um corpo, capaz de dar passagem a forças impessoais e singulares, constituindo-se como um bloco de sensações de perceptos e afectos que se sustentam e duram no tempo.

Nosso olhar-cartográfico buscou, dentro das limitações que lhe são inerentes, cartografar a duração dessas forças que ainda nos afetam, sondagem de uma espécie de estética ${ }^{6}$ das variações expressivas, na matéria em transformação.

Consideramos, aqui, a vida na sua vibração expressiva, protagonista de uma espécie de teatro sutil, no qual dramatizações de devires e de individuações? encontram-se como séries em variação incessante. 
Os devires do corpo-passagem é o que buscamos; ao visibilizarmos o espaço, visibilizamos o esforço de ancoragem de uma vida que pinta, com tintas, as forças constitutivas de seu "território existencial". Território subjetivo, silenciado pelo abandono, forrado pelos agenciamentos manicomiais, pintado como diferença de si. Buscamos traçar nas séries das repetições sempre aquilo que difere e denuncia um novo momento individuante.

Cada momento de nossa vida é uma espécie de criação. E, assim, como o talento do pintor se forma ou se deforma, em todo caso se modifica, pela própria influência das obras que produz, assim também cada um de nossos estados, ao mesmo tempo que sai de nós, modifica nossa pessoa, sendo a forma nova que acabamos de nos dar. Tem-se, portanto, razão em dizer que o que fazemos depende daquilo que somos; mas deve-se acrescentar que, em certa medida, somos o que fazemos e que nos criamos continuamente a nós mesmos (BERGSON, 2005, p. 7).

Buscamos, então, desenvolver no presente artigo dois movimentos de nossa pesquisa: o primeiro visa explorar o processo de criação tal como o concebemos, e o segundo constitui-se em fragmentos cartográficos que falam de nosso encontro com Luiz.

\section{Poiesis e SubjetivaÇão}

Nossa pesquisa debruçou-se sobre obras concebidas num espaço-tempo da loucura, produzidas por uma vida enclausurada que encontrou na pintura uma possibilidade de expressão. De nosso ponto de vista, a pintura revela-se como uma dobra expressiva que, por sua vez, suporta forças e estados do sujeito. Explorar as imagens refere-se a uma tentativa de trazer à tona algo do que estava em jogo no processo de criação da obra de arte, confrontando, pois, a obscuridade que permeia a conduta criadora.

Buscamos, então, problematizar a obra como plano de inscrição das forças que passam pelo corpo. Olhamos para a pintura como rastros de movimentos gestuais, que além de carregar a materialidade das camadas de tinta, carregam as tentativas de criação de territórios existenciais. ${ }^{8} \mathrm{Na}$ poiesis de si, a obra se faz, o corpo torna-se passagem para forças, ${ }^{9}$ o corpo torna-se possibilidade de expressão do sensível.

Duchamp (2005) desenvolve a ideia do artista como um ser mediúnico, cujo ato criador se passa da intenção à realização através de uma cadeia de relações totalmente subjetivas. Perguntamo-nos, então, que pode o corpo?

A criação, portanto, advém abertura possível do corpo para a passagem de forças, como movimento e passagem que se fazem em relação, nas dobras de um dentro e um fora. ${ }^{10}$ 
É assim que pensamos a criação: a partir do abandono do polo identitário, sedentário e molar do sujeito, ocorrendo somente quando o corpo entrega-se às dispersões moleculares dos fluxos que o penetram. Criação como devir que envolveria a emigração de certos territórios, que de sedentários se fazem nômades em movimentos constantes de desterritorialização e reterritorialização.

Mas, aqui, encontramos um paradoxo, em que a exaltação do impessoal está associada à procura máxima de singularidade. É preciso um "mínimo de eu" para que, na abertura às forças do impessoal, o sujeito não caia no caos. Segundo Deleuze (apud SCHÉRER, 2005, p. 137), "será necessário manter um mínimo, um mínimo de estratos, um mínimo de formas e de função, um mínimo de sujeito para dele extrair materiais, afetos e agenciamentos".

Falamos de uma dobra de subjetivação, uma captação de forças para um aumento da potência de agir. Entendemos, assim, o mínimo como aquilo que permite resistir e criar, sem cair numa dissolução e regressão ao indiferenciado. Vida minúscula, vida da clausura, cuja criação em movimento expressa potências de vida.

Para Deleuze e Guattari (2004), a obra de arte pode ser considerada como um bloco de sensações, isto é, um composto de perceptos e afectos. A partir desse ponto de vista, a obra existe em si mesma como um ser de sensação e, por isso mesmo, ela se conservaria, valendo por si mesma e excedendo qualquer vivido.

A sensação envolve o suporte e o material da própria obra de arte, a preparação da folha, o traço do pelo do pincel, o pote de tinta e muitas outras coisas antes de tudo isso. É difícil dizer onde começa e acaba a sensação. Pinta-se, esculpe-se, escreve-se com sensações. A duração do material, por mais curta que seja, possibilita a conservação da sensação. O que se conserva em si é o percepto e/ou afecto, que duram na eternidade que coexiste com essa curta duração do material. Dessa forma, a matéria torna-se expressiva, a sensação não é mais colorida. Ela torna-se colorante.

A arte buscaria arrancar o percepto das percepções, o afecto das afecções, extrair um bloco de sensações, um puro ser de sensações. Para isso, é preciso um método que varie segundo cada autor e que faça parte da obra, resultando em procedimentos diferentes e singulares."Sempre é preciso o estilo - a sintaxe de um escritor, os modos e ritmos de um músico, os traços e as cores de um pintorpara se elevar das percepções vividas ao percepto, de afecções vividas ao afecto" (DELEUZE; GUATTARI, 2004, p. 220).

Por entre a vida e obra de Luiz, nosso olhar buscou apreender algo de seu estilo. Estilo esse que se refere a uma espécie de falta de jeito, de fragilidade da saúde, de constituição fraca, de gagueira vital que é o "charme de alguém". Porém, o estilo não é de modo algum a pessoa. Segundo Deleuze e Parnet (1998, p. 13), "é o que faz apreender as pessoas como combinações e chances únicas que determinada combinação tenha sido feita". 
Que combinações frágeis circulam entre Luiz e a Oficina, entre Luiz e as tintas e que nos falam de sua potência de vida? Vida frágil essa, saúde incerta cujos acontecimentos conseguem (e)levar a vida ao estado de potência ou de "grande saúde".

Perguntamo-nos: em que ponto, em que momento as tintas jogadas no papel, os movimentos gestuais que pincelam as vibrações do corpo, em que ocasião se tornaram expressivas, capazes de configurar um estilo? Para Deleuze e Guattari (1997, p.124):

[...] o estilo constitui-se quando as qualidades expressivas ou matérias de expressão entram em relações móveis umas com as outras, as quais vão "exprimir" a relação do território que elas traçam com o meio interior dos impulsos e com o meio exterior das circunstâncias.

Propomos pensar o estilo como o espaço-tempo em que a pintura se constitui numa marca territorial, territorializante, uma espécie de assinatura. Para nós, o ato de pintar emerge de uma ferida. Pintar envolve um ultrapassamento do caos ou catástrofe para que a cor possa nascer. Assim, do forno-catástrofe que está sobre a tela, torna-se possível fazer brotar uma espécie de ovo ou cosmogênese. Porém, se a catástrofe transbordar completamente o quadro, pode haver uma espécie de destruição-consumação da pintura.

Para Deleuze (2007c), há dois momentos que envolvem o ato de pintar:

- o primeiro chamado de caos ou abismo, do qual sai a moldura. Este momento se subdivide em dois; no primeiro, não se vê nada; no segundo, algo sai, os grandes planos, a moldura, a geologia da pintura.

- o segundo momento é chamado de catástrofe, em que as grandes bases e a moldura são arrastadas, para que desse forno brote a cor.

É necessário que do caos-catástrofe da pintura saia a cor

Cada quadro como um novo começo de mundo

A dança química das cores

Os redemoinhos das forças

A saturação do eu

A abertura para o impessoal

Os sentidos dos matizes

Ser colorido pelo infinito

Eu e o quadro sermos um só

$\mathrm{O}$ caos que me fecunda

Germinamos 
Do olho vermelho

Brotam terras azuis

A paisagem se cria

Se recria

Planos são traçados

A armação, a moldura

Geometria do sensível

As cores devem ascender para que não se caia no limite onde todas se misturam, o cinza. O cinza, em que branco e preto se mesclam, cinza do fracasso. Mas há outro cinza, o cinza essencialmente luminoso, de onde as cores brotam, $\mathrm{o}$ cinza da mescla verde e vermelho, o cinza dinâmico.

Além da relação da pintura com o espaço, há a relação com o tempo, o tempo próprio da pintura. O quadro torna-se o lugar em que opera uma síntese do tempo que remete para a condição pré-pictórica do ato pictórico.

Podemos pensar o caos, não como o contrário da ordem, mas algo imponderável, incomensurável. Espécie de ser-nada ou nada-ser de onde emergem planos de consistência.

Tornar o caos visível pode ser feito a partir da aproximação com o ponto cinza, ponto fatídico entre o que devém e o que morre. Ponto em que não é branco nem preto, e porque é tanto branco como preto. Cinza porque não é quente nem frio. Cinza ponto, entre as dimensões, intersecção e entrecruzamento dos caminhos. Ponto cinza caos.

Ponto cinza caos como lugar de uma cosmogênese, o ovo, o gérmen. A gênese das dimensões envolveria, portanto, o ponto cinza caos e o ponto cinza matriz. No ponto cinza caos, o ponto cinza é não dimensional, cinza do negro e branco, cujos planos caem entre si. No ponto cinza matriz, ocorre um centramento, matriz das dimensões que podem advir, cinza do verde e vermelho. O ponto cinza estabelecido é capaz de saltar por cima de si mesmo, é o mesmo e não é o mesmo. Salta por cima de si mesmo e cria a ordem. O mesmo, porém, com uma forma completamente distinta, num momento completamente distinto.

O quadro torna-se espécie de ovo, matriz das dimensões. Torna-se necessário, então, que o ato de pintar ultrapasse o caos, que o salto seja dado. Matriz das dimensões e cores, síntese do tempo, começo de mundo.

O ato de pintar seria uma espécie de catástrofe em direção a uma luta com seus próprios fantasmas, luta contra seus próprios clichês. Os clichês seriam as bestas que se precipitam sobre a tela antes mesmo do pintor pegar em seu pincel. ${ }^{11}$

Trata-se, então, de olhar para a pintura como um dilúvio, é preciso afogar esses espectros, matá-los; é preciso passar pela catástrofe. 
Estabelecer sua própria catástrofe na tela em branco, fazer as marcas, marcas ao azar, como se faria uma espécie de "diagrama". ${ }^{12}$

Luiz, com seus círculos, linhas e espirais, marca a folha, traça uma espécie de diagrama, cujas linhas arrastam a tela de um extremo a outro, retratista das cores que dançam, devir-tempo que contém todos os relógios do mundo, relógios sem ponteiro ${ }^{13}$ que devém de sua própria duração. O diagrama, como essa zona que faz catástrofe sobre a tela, tudo é arrastado para uma catástrofe-gérmen, de onde sai a cor, o ritmo, o estilo.

Essa zona louca do quadro, de onde as dimensões e as cores brotam, esse cinza verde-vermelho a partir do qual as cores ascendem. Luiz pinta sua catástrofe, ultrapassa seu caos-gérmen, cria seu diagrama: mundo infinito dos minúsculos relógios sem ponteiros.

Ao seu modo, silencioso e atento, Luiz cria para si um novo território, em meio à clausura. Ao seu modo, torna-se, por um momento, filho de seus próprios acontecimentos. Luiz tem uma luz que insiste em brilhar apesar das trevas que o rodeiam.

\section{Um Sopro na Clausura}

Durante 40 anos internado num manicômio, essa vida azul, marcada pela frieza de um discurso médico, percorre, com seu corpo silencioso e magro, as superfícies possíveis do campo hospitalar. Ocupa, vaga e fantasmagoricamente, lugares minúsculos; silencia em meio aos gritos de horror e de dor. Esquizofrenia residual e abandono familiar se misturam no entendimento racional sobre sua vida. Mas a vida que pulsa em seu compelido e envelhecido corpo ainda resiste.

12 de janeiro de 1990. A mão toca o papel. O pincel, afogado em tintas, desliza por essa nova superfície. O corpo se torna um só gesto. Experimenta um novo espaço, um novo tempo. Novas latitudes e longitudes podem, enfim, advir. Um território de criação se faz possível; forças do fora se dobram nos traços gestuais. Tensões do corpo, deslocamentos da camada pictórica, limites borrados, idade avançada, desejo de pintar. Uma vida que começa a avermelhar, se torna mais quente e mais próxima de outros corpos.

Luiz, luz. Variações de um novo agenciamento. Nome, sentidos, brilho, pintura, cor, visibilidade. Enfim, um modo de dizer. O náufrago da ilha encontra seu deserto. Transtorna-o em povo; produz amizade com a solidão, agora povoada. Na Oficina de Criatividade, pode escutar a cançãozinha que lhe dá contorno, dobra-se, envelopando-o. Ali, o caos e a noite tornam-se seus aliados. Luiz, luz, luar, agora dobra uma linha em torno de si. Silente e impenetrável, encontra, todavia, uma linha de fuga que se expande em um território de ar do qual emanam vapores de uma máquina suave que, como meio associado, torna-se capaz de sustentar a produção de uma poiesis de si.

Pintar se tornou o acontecimento de Luiz em meio às paredes descascadas de um hospício. Sua pintura viva estende a linha do acontecimento puro, atmosfera cujo singular e impessoal são dobras um do outro. Com seu pincel fino 
e gasto, vai marcando uma a uma, o avesso de suas pinturas. Marca, imprimelhes o que tem de mais vivo em seu gesto. Interessa-lhe também o verso, plano da folha invisível para aqueles que apenas veem as evidências da pintura feita. Deixa transparecer as forças que vibram em suas pinceladas, espécie de composição tramada em estrutura e que carrega em si mesma níveis de sensação e movimento. Imagem multissensível cuja potência vital a transborda e atravessa. Singelo ritmo vital à sensação visual.

Há 20 anos, colocou-se a caminho desta pequena terra-oficina, onde lhe foi reservado um lugar especial. Confrontado ao cavalete, aguarda por atenções. Espera que lhe sejam oferecidas as tintas e o papel posto. Recomeça em seu deserto. Insiste e pinta o tempo de suas intensidades, aquilo que lhe concerne como duração vital. Marca a superfície em tateios de idas e voltas, cria um método fundado na intuição, e de seus gestos emergem grades, setas, círculos que nos parecem relógios sem ponteiros. Qual tempo estaria a indicar estes "relógios" soterrados em tintas e cores sobrepostas? O que dizer da sofreguidão por espaço, quando vemos a área pictórica plenamente preenchida e ainda assim enigmática? O que dizer dessa insistência, mesmo quando percebemos que, em seu atual estado, o pintor beira uma cegueira física? Pintando, a partir do seu olhar de dentro, o mundo, quem sabe, segue nublado.

O corpo espera sentado num mundo em que sombras e vultos tentam se fazer nítidos. Gritos entoam a música de fundo; o silêncio de si preenche o coração que ainda bate. Eis uma voz que pergunta: "Seu Luiz, vamos à Oficina?" Um monossilábico "sim" sai de sua boca, seu frágil corpo ergue-se e ancora-se naquele anjo que o guia, sem quase nada poder para salvá-lo. Retoma o caminho que antes percorria solitário. Com passos tateantes, busca adivinhar os obstáculos do piso esburacado. O caminho até a Oficina, antes conduzido pelos olhos, agora é conduzido por pés que se arrastam e pintam, ao rés do chão, traçados de uma geografia transformada pelo tempo.

Seu braço move-se em direção à folha. Tenta adivinhar, em meio às tintas ressecadas, aquela que permanece fresca e que marcará o papel através dos gestos. Deslizamento sobre a superfície, uma escrita numérica marca o início do movimento com ritmo quebrado, 1, 2, 3, 4, 5,9, divisão do papel em quadrantes, em grades, linhas retas que se cruzam, que trancam, aprisionam ou suportam. Círculos dentro de quadrados, espirais que movimentam as marcas de tintas, compõem e preenchem os espaços em branco. Delicadeza e detalhismo se confundem, camadas de veladuras e transparências enevoam a visão.Vida e cores misturadas.

Como falar de Luiz, sem falar de suas obras? Como falar do limite existente entre as forças que atravessaram seu corpo, e cujas marcas pictóricas duram no olhar de quem as enxerga? Como não falar das misturas entre as forças e os fluxos, entre as cores e a expressão, entre os tempos e as variações?

Como não falar sobre a vitalidade de uma vida que pinta, na qual o subjetivo é capaz de se tornar tangível, com seus blocos de linhas e cores, relógios inacabados, números ritmados, que pulsam e duram, nos múltiplos sentidos em que nossos olhares podem evocar. 
Mas, para além das misturas no fundo dos corpos, para além dos estados de coisas, nos interessa os acontecimentos incorporais que deslizam pela superfície, e que resultam dessas misturas. Luiz pinta a folha soterrando-a com seus gestosmassa, suas marcas-labirinto, deserto à espera de um acontecimento, capaz de lhe fazer território, território de existência.

Luiz com seu corpo frágil, com a potência de vida que sua pintura instaura no ambiente inóspito de um Hospital Psiquiátrico, nos fala de um ultrapassamento, resistência a essas forças disciplinadoras que se impõem ao dentro tentando organizá-lo. Luiz rompe com elas quando instaura a possibilidade de expressão em meio às tintas. Quando o sofrimento em meio à clausura deixa de ser doença e se torna um meio para a saúde.

Um corpo que possa viver o inviável, suportar o insuportável, o "corpo sem órgãos" capaz de passar por estados de dobramentos, torções. Na entrega do corpo às suas feridas, na exposição ao sofrimento que delas provém, o corpo aumenta sua potência de agir. Sua pintura passa pela catástrofe, ultrapassa a ferida e dá possibilidade do caos germinar.

Trata-se, então, de estar à altura daquilo que nos acontece. No acontecimento operado entre o corpo de Luiz e o hospital, seu percurso possibilita agenciar-se à Oficina, às tintas, a partes de si. Ao seu modo, silencioso e calmo um "diagrama" nasceu, por entre o corpo, a folha, as tintas, as forças, a passagem, o impessoal, o devir. Um "território existencial" foi traçado em meio às relações entre o singular e o impessoal. De forma paradoxal, Luiz criou sua própria arte que é capaz de se sustentar, com seus blocos de sensações que duram em nosso olhar e clamam por um povo que ainda está por vir.

Uma vida em fragmentos, enclausurada por 60 anos, que expressou, numa composição cromática, toda potência que lhe habita, que passa e faz passar; uma vida-obra em imagem-tempo que nos fala de resistência e criação. Uma vida cujas variações expressivas cintilam os acontecimentos que a atravessaram, uma vida que não remete a uma história pessoal, mas à abertura para a invenção de novos devires. Uma vida que pode nos contar sobre uma outra história da loucura.

\section{Notas}

Bousquet (apud DELEUZE, 2007a, p. 152)

${ }^{2}$ Mais informações sobre a Coleção Luiz Guides pode ser obtida no site http://www.eusouvoce. com.br/pag_artistas.htm

Para Suely Rolnik (2006, p. 23), a noção de cartografia difere de um mapa, pois não se fecha em uma figura representativa "[...] é um desenho que acompanha e se faz ao mesmo tempo que os movimentos de transformação da paisagem".

${ }^{4}$ Para Deleuze (2005), a subjetivação se faz por dobras.

${ }^{5}$ Para Deleuze (2007b, p. 62), "a tarefa da pintura é definida como a tentativa de tornar visíveis as forças que não são visíveis".

${ }^{6}$ Estética que vem do grego Aistheton, "aquilo que é sensível; relativo a aquilo que se sente".

Segundo Deleuze (2006, p. 346), "individuação é o ato da intensidade que determina as relações diferenciais a se atualizarem, de acordo com as linhas de diferençação, nas qualidades e nos extensos que ela cria".

${ }^{8}$ Segundo Guattari (2008, p. 19), a subjetividade pode ser descrita como o "conjunto das condições que torna possível que instâncias individuais e/ou coletivas estejam em posição de emergir como 
território existencial auto-referencial, em adjacência ou em relação de delimitação com uma alteridade ela mesma subjetiva".

${ }^{9}$ Ideia do corpo tornando-se veículo para as forças que passam (SANT'ANNA, 2005).

${ }^{10}$ Para Rolnik (1997), podemos considerar o fora como uma nascente de linhas de tempo que se fazem ao sabor do acaso, cujo, lançamento torna-se dobra que se concretiza e se espacializa num território de existência, seu dentro. A concretização e espacialização fazem-se e refazem-se continuamente, numa espécie de duração intrínseca.

${ }^{11}$ Para Pedrosa (1996), o problema da criação consistia em libertar-se de associações mentais já feitas, já acorrentadas, automaticamente, a certas fórmulas.

${ }^{12}$ Diagrama para Deleuze (2007b, p. 104) “é o conjunto operatório dos traços e manchas, das linhas e zonas".

${ }^{13}$ Há um artigo sobre as pinturas de Luiz que traz a idéia de "relógios sem ponteiros" (NEUBARTH, 2003).

\section{REFERÊNCIAS}

BERGSON, H. Evolução criadora. São Paulo: Martins Fontes, 2005.

DELEUZE, G. Foucault. São Paulo: Brasiliense, 2005.

DELEUZE, G. Diferença e repetição. Rio de Janeiro: Graal, 2006.

DELEUZE, G. Lógica do sentido. São Paulo: Perspectiva, 2007a.

DELEUZE, G. Francis Bacon: a lógica da sensação. Rio de Janeiro: J. Zahar, 2007b.

DELEUZE, G. El concepto de diagrama. Buenos Aires: Cactus, 2007c.

DELEUZE, G.; GUATTARI, F. Mil Platôs: capitalismo e esquizofrenia. São Paulo: Ed. 34, 1997. v. 4.

DELEUZE, G.; GUATTARI, F. O que é a filosofia? Rio de Janeiro: Ed. 34, 2004.

DELEUZE, G.; PARNET, C. Diálogos. São Paulo: Escuta, 1998.

DUCHAMP, M. O ato criador. In: Caderno de textos da Quinta Bienal de Artes Visuais do Mercosul. Porto Alegre: Fundação Bienal do Mercosul, 2005, p. 27-28.

GUATTARI, F. Caosmose: um novo paradigma estético. São Paulo: Editora 34, 2008.

NEUBARTH, B. Relógios sem ponteiros: desvelando uma história de vida. In: FONSECA, T. M. G.; KIRST, P. G. (Org.). Cartografias e devires: a construção do presente. Porto Alegre: UFRGS, 2003. p. 375-395.

PEDROSA, M. Forma e percepção estética: textos escolhidos. São Paulo: Universidade de São Paulo, 1996. v. II. 
ROLNIK, S. Cartografia Sentimental: transformações contemporâneas do desejo. Porto Alegre: Sulina, UFRGS, 2006.

ROLNIK, S. Uma insólita viagem à subjetividade fronteiras com a ética e a cultura . 1997. Disponível em: <http://caosmose.net/suelyrolnik/textos/sujeticabourdieu.doc>. Acesso em: 25 jul. 2009.

SANT'ANNA, D. B. de. Corpos de passagem: ensaios sobre a subjetividade contemporânea. São Paulo: Estação Liberdade, 2005.

SCHÉRER, R. Sem rosto: limites das prerrogativas do eu (moi) na criação - a idéia de mínimo em Deleuze. In: MACIEL JUNIOR, A. et al. (Org.). Polifonias: clinica, política e criação. Rio de Janeiro: Contracapa, 2005. p. 131-139.

Recebido em: 31 de janeiro de 2011 Aceito em: 17 de agosto de 2011 
